\title{
Optimization of biohydrogen production by Clostridium butyricum EB6 from palm oil mill effluent using response surface methodology
}

\begin{abstract}
Clostridium butyricum EB6 successfully produced hydrogen gas from palm oil mill effluent (POME). In this study, central composite design and response surface methodology were applied to determine the optimum conditions for hydrogen production $(\mathrm{Pc})$ and maximum hydrogen production rate (Rmax) from POME. Experimental results showed that the $\mathrm{pH}$, temperature and chemical oxygen demand (COD) of POME affected both the hydrogen production and production rate, both individually and interactively. The optimum conditions for hydrogen production $(\mathrm{Pc})$ were $\mathrm{pH} 5.69$, 36degreeC, and 92g COD/1; with an estimated Pc value of $306 \mathrm{ml} \mathrm{H} 2 / \mathrm{g}$ carbohydrate. The optimum conditions for maximum hydrogen production rate (Rmax) were $\mathrm{pH} 6.52$, 41degreeC and 60g COD/1; with an estimated Rmax value of $914 \mathrm{ml} \mathrm{H} 2 / \mathrm{h}$. An overlay study was performed to obtain an overall model optimization. The optimized conditions for the overall model were $\mathrm{pH} 6.05,36 \mathrm{degreeC}$ and $94 \mathrm{~g} \mathrm{COD} / 1$. The hydrogen content in the biogas produced ranged from $60 \%$ to $75 \%$.
\end{abstract}

Keyword: Biohydrogen; Clostridium butyricum EB6; Response surface methodology; POME 